\title{
EFFECT OF EARLY SURGERY ON OUTCOME IN PERFORATION PERITONITIS
}

Tika Ram Bhandari ${ }^{1}$, Rajesh Poudel ${ }^{1}$, Kailash Chandra ${ }^{2}$

\section{ABSTRACT}

\section{BACKGROUND}

Early diagnosis and emergent surgical management of perforation peritonitis remain themainstay of treatment. The aim of study was to find the effect of early surgery on postoperative outcome in patients with perforation peritonitis.

\section{MATERIALS \& METHODS}

A retrospective medical report of 200 patients who underwent exploratory laparotomy and proceed for perforation peritonitis from July 2015 to December 2016 was studied. Patients were divided into two groups based on the time of surgery i.e: Early ( $<6$ hours) and late ( $\geq 6$ hours) intervention groups. All perioperative outcome of surgery were analyzed.

\section{RESULTS}

Late intervention patients were more likely to develop complications $(34.3$ and $17.8 \%, \mathrm{P}<0.05)$ and mortality $(14$ and 6 $\%, \mathrm{P}<0.05)$ in comparisionto early intervention patients and had significantly higher median time to resumption of normal diet (5and 2.8 days, length of hospital stay ( 15 and 9 days) and length of ICU stay ( 8 and 4 days) $(\mathrm{P}<0.05)$. The time to operation ( $\geq 6$ hours) and preoperative hypotension were independent risk factors for postoperative complications in multivariate analysis.

\section{CONCLUSION}

Early surgical intervention within six hours along with broad spectrum antibiotics preceded by adequate aggressive resuscitation improves postoperative outcomes in perforation peritonitis.

KEYWORDS: Early surgery, Perforation Peritonitis, Complication

1. Lecturer, Department of Surgery, UCMS, Bhairahawa

2. Professor, Department of Surgery,UCMS, Bhairahawa

\author{
Corresponding author \\ Dr. Tika Ram Bhandari \\ Lecturer, Department of Surgery, \\ Universal College of Medical Sciences(UCMS), \\ Bhairahawa, Nepal \\ Email: tikanme@hotmail.com
}




\section{INTRODUCTION}

Gastrointestinal perforations constitute one of the commonest surgical emergency encountered by surgeons. ${ }^{1,2}$ Management of these patients continues to be highly demanding despite the advances made in diagnosis and surgical therapy. Perforation peritonitis is highly fatal with a reported death rate of up to $56 \% .{ }^{1-4}$ Many reports have described surgical intervention within $8-24 \mathrm{~h}$ after the arrival of patient at the emergency department decreases death rates. ${ }^{5}$ The general belief of surgeons is that the earlier one operates, the better the outcome. However, only few studies have reported the issue of time to intervention and how early time has not been cosidered. In our day to day work, our experience is that the sooner we do surgery and close the perforation, the better the postoperative outcome.Our patients with perforation peritonitis got operated within the first 2-4 h after their arrival or diagnosis. Though, we could not find any large study that proven operations in the first 2-4 h, probably because most of the patients need aggressive resuscitation before the surgery. We aimed that operating within the first $6 \mathrm{~h}$ after diagnosis of perforation peritonitis would improve outcomes outcomes in perforation peritonitis.

\section{MATERIALS \& METHODS}

This was a retrospective study, performed in the Department of Surgery, Universal College of Medical Sciences Bhairahawa, Nepal from July 2015 to December 2016. The total 200 patients who underwent exploratory laparotomy and further proceed for perforation peritonitis presenting to the surgical emergency were included in the study. Approval from Institutional review committee ,Universal College of Medical Sciences was taken for the study (UCMS/ IRC/ 026/17)

On the basis of the time of surgery ( after diagnosis to time of surgery ), patients were categorized into two groups i.e: Early (group I , $<6$ hours) and late group II, $\geq 6$ hours) intervention groups. Baseline demographic characteristics, clinical features at the time of presentation, comorbid conditions and radiological investigations of patients were compared for both groups. After patient clinically diagnosed with perforation peritonitis, the patients were prepared for exploratory laparotomy. Operative findings were noted during surgery and the source of peritonitis was found and managed accordingly. All patients were prescribed parenteral broad-spectrum antibiotics and fluids; oral feeding was started after the appearance of bowel sounds. The postoperative complications, the length of stay in ICU and length of stay in hospital ofwere recorded.

\section{STATISTICALANALYSIS}

All continuous variables were expressed as proportion, mean \pm standard deviation and median (range) as appropriate and compared with the student t-test or Mann-Whitney test. Categorical values were compared with the chi-square test. Pearson correlation coefficient was used to assess for any correlation between the time to intervention $(<6 \mathrm{hr}$ and $\geq 6 \mathrm{hr}$ ) to the ICU length of stay (LOS) and the total hospital LOS. To assess the clinical predictors of outcomes of surgery in perforation peritonitis, multivariate logistic regression analysis was also performed. Statistical analysis was done with statistical software SPSS version 22.0 (Statistical Package for the Social Sciences). A p-value $<0.05$ was considered statistically significant.

\section{RESULTS}

Out of 200 perforated peritonitis patients, $57 \%$ were male .The mean age was $40 \pm 7$ years. Tachycardia was the commonest physical findings $(65 \%$ in early intervention vs. $68 \%$ in late intervention), followed by hypotension ( $32 \%$ vs. $34 \%$ ) and abdominal distension (32\% vs. $28 \%$ ). However, abdominal pain was commonest symptoms (94\% vs. $92 \%$ ) followed by altered bowel habit (65\% vs. 60\%) and nausea vomiting ( $40 \%$ vs. 46 ). Comorbid conditions were found in $16 \%$ of patients. The most common comorbidity was respiratory problems $(12 \%$ vs. $16 \%)$, followed by diabetes $(11 \%$ vs. $12 \%)(\mathrm{P}=0.234)$ as shown in Table 1 .

Table 1. Patient characteristics

\begin{tabular}{|l|l|l|l|}
\hline Variable & $\begin{array}{l}\text { Early Intervention } \\
(\mathrm{n}=104)\end{array}$ & $\begin{array}{l}\text { Late Intervention } \\
(\mathrm{n}=96)\end{array}$ & $\mathrm{P}$ \\
\hline Age (mean+-SD) & $\ldots$ & $49.2 \pm 17$ & 0.234 \\
\hline Sex \% & & & \\
Male & 58 & 52 & 0.123 \\
female & 42 & 48 & 0.243 \\
\hline Comorbidity \% & & & 0.321 \\
Diabetes mellitus & 11 & 12 & 0.543 \\
Respiratory disease & 12 & 16 & 0.435 \\
Renal disease & 8 & 11 & 0.234 \\
Hypertension & 8 & 6 & \\
\hline
\end{tabular}

\section{SD: Standard Deviation}

Pneumoperitoneum was found in $77 \%$ vs. $75 \%$ in (group I and group II ) patients on erect posture chest X-ray. Abdominal X-ray had shown multiple air fluid levels in the erect position in $29 \%$ vs. $24 \%$ ) patients. Hyponatremia ( $21 \%$ vs. $20 \%$ ), hypokalemia (12\% vs. $19 \%$ ) and elevated serum creatinine (12\% vs. 18\%) were documented . Gastroduodenal perforation was most common cause of perforation peritonitis due to acid peptic disease (43\% vs. $44 \%$ ) followed 
by appendicitis (17\% vs. $15 \%)$ in both groups as shown in Table 2. The commonest perforation site was duodenum ( $40 \%$ vs. $37 \%$ ) in early vs. late intervention groups. We did not find any significant difference between the two groups in respect to causes of perforation and site of perforation $(\mathrm{P}<0.05)$ as shown in Table 3.

Table 2.Clinical parameters

\begin{tabular}{|l|l|l|l|}
\hline Variable $\%$ & $\begin{array}{l}\text { Early Intervention } \\
(\mathrm{n}=104)\end{array}$ & $\begin{array}{l}\text { Late Intervention } \\
(\mathrm{n}=96)\end{array}$ & $\mathrm{P}$ \\
\hline Abdominal pain & 94 & 92 & 0.142 \\
Altered bowel habit & 65 & 60 & \\
Nausea and vomiting & 40 & 46 & \\
Abdominal distention & 32 & 28 & \\
H/O of NSAIDS & 12 & 14 & 0.134 \\
$\quad>$ 6months) & 65 & 68 & 0.324 \\
Tachycardia & & 34 & \\
$\quad$ pulse $>100$ beats/mins) & 32 & & \\
Hypotension & & & \\
\hline
\end{tabular}

Table 3.Etiology and site of perforation peritonitis

\begin{tabular}{|l|l|l|}
\hline Parameter & $\begin{array}{l}\text { Early Intervention } \\
(\mathrm{n}=104)\end{array}$ & $\begin{array}{l}\text { Late Intervention } \\
(\mathrm{n}=96)\end{array}$ \\
\hline Causes of perforation, \% & & \\
Acid peptic disease & 43 & 44 \\
Appendicitis & 17 & 15 \\
Typhoid & 10 & 11 \\
Tuberculosis & 8 & 7 \\
Trauma & 6 & 6 \\
Malignancy & 2 & 3 \\
Bowel strangulation & 2 & 1 \\
Band obstruction perforation & 1 & 2 \\
Amoebic caecal perforation & 1 & 1 \\
& & \\
Site of perforation, \% & 40 & 37 \\
Duodenum & 26 & 23 \\
Ileum & 17 & 16 \\
Appendix & 9 & 6 \\
Stomach & 4 & 2 \\
Sigmoid colon & 2 & 2 \\
Caecum & 1 & 1 \\
Transverse colon & 1 & \\
Descending colon & & \\
\hline
\end{tabular}

Median time to intervention was $2.85 \mathrm{~h}$ (range $2-5$ ) and $7.23 \mathrm{~h}$ (range 6-18), in the two groups respectively.Overall postoperative complication was detected in 56 patients (28\%). Wound infection (33\% in Group I vs. 36\% in Group II) was most common complications followed by dyselectrolytaemia (23\% vs. $22 \%)$. The overall mortality rate was ( $6 \%$ vs. $14 \%)$. Septicemia due to fecal peritonitis, respiratory complications, pulmonary embolism, and late presentation were considered for the causeof death in both groups. We found statistically significant difference in morbidity and mortality between the two groups $(\mathrm{P}=0.022)$. Time to surgery $([2.85 \pm 2.3]$ vs. $[7.23 \pm 8.4] \mathrm{h})$, median hospital LOS (9 [1-21] vs. 15 [7-36] days), and median ICU LOS (4 vs. 8 days) was shorter in group I than Group II as shown in Table 4. The Late intervention group had significantly longer median time to resumption of normal diet (2.8 [1-5] vs. 5 [0-15] days, $\mathrm{P}=0.005)$. Moreover, there was a correlation between the time to surgery and ICU LOS ( $\mathrm{r}=$ 0.26, $\mathrm{P}=0.01)$ and LOS hospital $(\mathrm{r}=0.16, \mathrm{P}=0.01)$ respectively.In multivariate analysiss, time to operation in early vs late, (OR; 2.478; 95\% CI; [1.002 to 4.86]; $\mathrm{P}=0.005)$ and preoperative hypotension (OR, 2.005; 95\% CI; [ 1.021 to 3.487], $\mathrm{P}=0.005$ ) were significant risk factors for post operative complications as shown in Table 5.

Table 4. Clinical outcomes of early intervention and late intervention patients

\begin{tabular}{|l|l|l|l|}
\hline variable & $\begin{array}{l}\text { Early Intervention } \\
(\mathrm{n}=104)\end{array}$ & $\begin{array}{l}\text { Late Intervention } \\
(\mathrm{n}=96)\end{array}$ & $\mathrm{P}^{*}$ \\
\hline Time to surgery (hr)(mean $\pm \mathrm{SD})$ & $2.85 \pm 2.3$ & $7.23 \pm 8.4$ & 0.001 \\
\hline Operative time (min) & $90.5(60-156)$ & $105(70-168)$ & 0.027 \\
\hline Complications, $\%$ & 17.8 & 34.3 & 0.022 \\
Wound infection & 33 & 36 & \\
Dyselectrolytemia & 23 & 22 & 16 \\
Intraabdominalabscess & 16 & 15 & 9 \\
Respiratory problems & 15 & 2 & 14 \\
Burst abdomen & 11 & 2 & 0.005 \\
Anastomotic leak & 6 & $5.0(0-15)$ & 0.014 \\
Mortality & & $15(7-36)$ & 0.012 \\
\hline Time to resumption of normal diet (days) & $2.8(1-5)$ & $8(1-26)$ & \\
\hline Length of hospital stay (days) & $9(1-21)$ & $4(1-9)$ & \\
\hline Length of ICU stay (days) & & & \\
\hline
\end{tabular}

*Pvalue $<0.05$

Table 5.The relationship between the clinical predictors and postoperative outcomes

\begin{tabular}{|l|l|l|l|}
\hline Variable & OR & $95 \% \mathrm{CI}$ & $\mathrm{P}^{*}$ \\
\hline $\begin{array}{l}\text { Preoperative hypotension } \\
\text { Time to surgery } \\
\text { Late }(>6 \text { hours) }\end{array}$ & 2.005 & $(1.002-1.009)$ & 0.005 \\
\hline
\end{tabular}

OR;odds ratio, CI; confidence interval, *P value $<0.05$ 


\section{DISCUSSION}

Treatment of perforation peritonitis remains to be extremely challenging regardless of the improvements in diagnosis and operative treatment. We found that surgery within the first six hour after diagnosis of perforation peritonitis had good outcomes in relations of earlier resumption of normal diet, shortening the length of stay in hospital and length of stay in ICU. Our overall mortality rate was $10 \%$, which is lower than reported by other studies. ${ }^{4-7}$ In comparision to early intervention patients, late intervention patients develop more postoperative complications $(34.3 \%$ vs. $17.8 \%, \mathrm{P}=0.022)$. Perforation peritonitis is a fatal surgical emergency and needs effective resuscitation and appropriate prompt surgery. Early definitive diagnosis, early broad-spectrum antibiotic treatment, and early surgery is accepted as standard treatment for these patients. ${ }^{8-10}$ In the present study, most of our early intervention group patients had surgery even earlier within a median time of $2.85 \pm 2.3$ hours. The most usualcause for a delay in operation is trouble in making the accurate diagnosis. Most of patients are dehydrated, septic and hypotensive, who needs aggressive resuscitations causing in knowinglylate operation ${ }^{11}$. Though, it is important to think that cause control of the infection is the importance in the treatment of any perforation peritonitis patient. In spite ofseveral scoring systems and models had to distinguish between primary and secondary peritonitis, the diagnosis predicting mortality and morbidity is quietchallenging ${ }^{12-14}$ and the most important thing remains timelyscientific diagnosis . Generally, patient get a plain film to rule out gas under both domes of the diaphragm $^{14-18}$ which is most common and feasible test. Most of the time, we do computed tomography techniques to confidently rule out the need for immediate surgery. ${ }^{19}$

The many studies stated upto $72 \%$ mortality rate when there is delay in surgery. The mortality rate of $16.4 \%$ reported with median time to surgery of 8.4 hour, while high risk of death during hospital admission will be there if interval $>14 \mathrm{~h}$ from diagnosis to surgery in patients with septic shock. ${ }^{20-22}$ These patients are seen almost immediately in our institution by inhouse acute care surgeon. As it is established that early surgical intervention is important in decreasing morbidity and mortality in perforation peritonitis patients. Though, significanceof early is not clearly defined in previous study. So this studyconcentrated on that. So, together with other studies, our study will help to the define the early intervention. Early surgical intervention is associated with high survival reported in very few studies ${ }^{23,24}$. We reported good postoperative outcomes with earlier surgical intervention (within the first $6 \mathrm{~h}$ ) and high rate of death among late intervention group. Also, the duration of hospital and ICU stay was less in early intervention group.
To the best of our knowledge, we believe that it is the first study in our part of world to clearly showing that operating early, within the first 6 hour in patients with perforation peritonitis, would shorten both ICU LOS and hospital LOS . Other studies including that of SM Fakhry et al. ${ }^{25}$ has shown that early and aggressive intervention is crucial. However, in the other study, patients undergoing early and aggressive treatment had significantly lower mortality ${ }^{26}$, though, timing from definite diagnosis to the operation was not reported. The idea of the idealtime resuscitation with concurrentcause control should be applied in patients with perforation peritonitis as well. We had a statistically significant difference in mortality between the two groups and our overall low mortality rate in the earlier operative group of $6 \%$; is one of the lowest reported. We believe that our low mortality rate was the result of early surgery and in-house acute care surgery practice.

Similar to the other retrospective study, we could not account for the number of surgeons involved in each patient's care and the variability between surgeons. Moreover, we defined time to surgery as the interval from being diagnosed by the surgery team in the emergency department to undergoing the operation; we did not look at how long patients had symptoms and how long patients might have waited after first coming to the emergency department,nor did we take into account when the patients were transferred from other institutions. Additional prospective larger studies are suggested to validate our results.

\section{CONCLUSION}

Early surgery within six hours along with broad spectrum antibiotics preceded by adequate aggressive resuscitation and correction of electrolyte imbalances improves postoperative outcomes in perforation peritonitis.

\section{CONFLICT OF INTERESTS}

The all authors declare that there is no conflict of interests regarding the publication of this paper. 


\section{REFERENCES}

1. Dorairajan LN, Gupta S, Deo SV, Chumber S, Sharma LK Peritonitis in India a decade's experience. Trop Gastroenterol Off J Dig Dis Found. 1994;16(1):33-38.

2. Ali N, Gali BM. Causes and treatment outcome of perforation peritonitis in northeastern Nigeria. SurgPract. 2010; 14(3):92 $-96$.

3. Andersen HK, Lewis SJ, Thomas S. Early enteral nutrition within $24 \mathrm{~h}$ of colorectal surgery versus later commencement of feeding for postoperative complications. Cochrane Libr ; 2006

4. Batra P, Gupta D, Rao S, Narang R, Batra R. Spectrum of gastrointestinal perforation peritonitis in rural central India. $J$ Mahatma Gandhi Inst Med Sci. 2013;18(1):44-48.

5. Bali RS, Verma S, Agarwal PN, Singh R, Talwar N. Perforation peritonitis and the developing world. ISRNSurg;2014.

6. Afridi SP, Malik F, Ur-Rahman S, Shamim S, Samo KA. Spectrum of perforation peritonitis in Pakistan: 300 cases Eastern experience. World JEmerg Surg. 2008;3(1):1.

7. Nespoli A, Ravizzini C, Trivella M, Segala M. The choice of surgical procedure for peritonitis due to colonic perforation. Arch Surg. 1993;128(7):814-818.

8. Capoor MR, Nair D, Chintamani MS, Khanna J, Aggarwal P, Bhatnagar D, et al. Role of enteric fever in ileal perforations: An overstated problem in tropics? Indian J Med Microbiol. 2008; 26(1):54.

9. Singh R, Kumar N, Bhattacharya A, Vajifdar H, others. Preoperative predictors of mortality in adult patients with perforation peritonitis. Indian J Crit Care Med. 2011;15(3) $: 157$.

10. Wittmann DH, Schein M, Condon RE. Management of secondary peritonitis. Ann Surg. 1996;224(1):10

11. Mulier S, Penninckx F, Verwaest C, Filez L, Aerts R, Fieuws $S$, et al. Factors affecting mortality in generalized postoperative peritonitis: multivariate analysis in 96 patients. World J Surg. 2003;27(4):379-384.

12. Maetani S, Tobe T. Open peritoneal drainage as an effective treatment of advanced peritonitis. Surgery. 1981;90(5) :804-809.

13. Agrawal S, Sharma D, Raina VK. Arterial $p H$ and arterial oxygenation are not essential for risk stratification in perforation peritonitis. Indian $J$ GastroenterolOff $J$ Indian SocGastroenterol. 1998;18(1):5-6.

14. Akriviadis EA, Runyon BA. Utility of an algorithm in differentiating spontaneous from secondary bacterial peritonitis. Gastroenterology. 1990;98(1):127-133.
15. Runyon BA, Hoefs JC. Ascitic fluid analysis in the differentiation of spontaneous bacterial peritonitis from gastrointestinal tract perforation into ascitic fluid. Hepatology. 1984;4 (3):447-450.

16. Hinchey EJ, Schaal PG, Richards GK. Treatment of perforated diverticular disease of the colon. Adv Surg. 1977;12:85-109.

17. Borushok KF, Jeffrey Jr RB, Laing FC, Townsend RR. Sonographic diagnosis of perforation in patients with acute appendicitis. AJR Am J Roentgenol. 1990;154(2):275-278.

18. Bansal J, Jenaw RK, Rao J, Kankaria J, Agrawal NN. Effectiveness of plain radiography in diagnosing hollow viscus perforation: study of 1,723 patients of perforation peritonitis. EmergRadiol. 2012;19(2):115-119.

19. Glazer GM, Buy JN, Moss AA, Goldberg HI, Federle MP. CT detection of duodenal perforation. Am J Roentgenol. 1981;137 (2) :333-336.

20. Jhobta RS, Attri AK, Kaushik R, Sharma R, Jhobta A. Spectrum of perforation peritonitis in India-review of 504 consecutive cases. World JEmerg Surg. 2006; 1(1):1.

21. Chakma SM, Singh RL, Parmekar MV, Singh KH, Kapa B, Sharatchandra KH, et al. Spectrum of perforation peritonitis. $J$ ClinDiagn Res. 2013;7(11):2518-20.

22. Nagorney DM, Adson MA, Pemberton JH. Sigmoid diverticulitis with perforation and generalized peritonitis. Dis Colon Rectum. 1985;28(2):71-75.

23. Inui A, Nitta A, Yamamoto A, Kang S-M, Kanehara I, Tanaka H, et al. Generalized peritonitis with pneumoperitoneum caused by the spontaneous perforation of pyometra without malignancy: report of a case. Surg Today. 1999;29(9):935938.

24. Maurer CA, Renzulli P, Mazzucchelli L, Egger B, Seiler CA, Büchler MW. Use of accurate diagnostic criteria may increase incidence of stercoral perforation of the colon. Dis Colon Rectum. 2000;43(7):991-998.

25. Fakhry SM, Brownstein M, Watts DD, Baker CC, Oller D. Relatively short diagnostic delays $(<8$ hours) produce morbidity and mortality in blunt small bowel injury: an analysis of time to operative intervention in 198 patients from a multicenter experience. J Trauma Acute Care Surg. 2000;48(3) :408-415.

26. Sharma K, Kumar M, Batra UB. Anesthetic management for patients with perforation peritonitis. J Anaesthesiol Clin Pharmacol 2013;29(4). 